\title{
PLURALISMO JURÍDICO, TECNOLOGIA E A RESOLUÇÃO ONLINE DE CONFLITOS
}

\author{
LEGAL PLURALISM, TECHNOLOGY AND ONLINE DISPUTE RESOLUTION
}

Flávia de Almeida Montingelli Zanferdini*

Rafael Tomaz de Oliveira**

\begin{abstract}
Resumo: A internet é fenômeno social global, com grande impacto nas relações sociais. Os métodos de solução de conflitos em espaço cibernético (ODR - online dispute resolution) são essenciais para solução dos litígios que surgem no mundo virtual, em especial para aqueles cujo custo econômico da demanda, a distância geográfica, as barreiras culturais, de idioma e as diferenças nos ordenamentos jurídicos vigentes inviabilizam um encontro presencial. A ideia surgiu em estudos acadêmicos na década de 90, nos Estados Unidos, com o escopo de resolver disputas decorrentes do comércio eletrônico e hoje é um tema que vem merecendo estudo no Direito, em especial sob o enfoque do pluralismo jurídico que pressupõe a integração entre o modelo oficial de jurisdição e as demais manifestações plurais de resolução de conflitos. A tecnologia altera paradigmas, assim, pensar nos métodos ODR como modelo oficial de resolução de disputas não é mais ficção cientifica.
\end{abstract}

Palavras chave: Resolução de conflitos online; Pluralismo; Tecnologia; Direito.

\begin{abstract}
Internet has a social and global impact in social relations. Online Dispute Resolution is essencial for conflicts that arise from the online relationships. The presencial meeting in those disputes is very difficult and expensive due to cultural barriers, high economic costs and differences between languages and the legal systems. The idea was developed in the United States in an academic study in the 90's. The purpose was to solve commercial disputes from e-commerce. Today it is an important issue to study in Law, in particular from the point of view of legal pluralism, which presupposes integration between the official model of jurisdiction and the other plural manifestations of conflict resolution. Technology changes paradigms and to believe that ODR will be the most important and the main system in dispute resolution is not anymore science fiction.
\end{abstract}

Keywords: ODR Online dispute resolution; Pluralism; Technology; Law

\section{INTRODUÇÃO}

\footnotetext{
"Todas as sociedades e todos os grupos sociais (incluindo tanto famílias como nações) precisam encontrar meios efetivos de resolver as disputas que surgem e com as comunidades cibernéticas isso não é diferente". ${ }^{1}$
}

O mundo se tornou, como diz o clichê, bem menor com o uso de tecnologias.

\footnotetext{
* Doutora em Direito pela PUC/SP. Professora Titular do Programa de Pós-Graduação e Graduação em Direito da UNAERP (Universidade de Ribeirão Preto, Estado de São Paulo). Juíza de Direito (TJ/SP). E-mail: fzanferdini@ hotmail.com

** Doutor em Direito pela UNISINOS-RS. Professor Titular do Programa de Pós-Graduação e Graduação em Direito da UNAERP (Universidade de Ribeirão Preto, Estado de São Paulo) e das Faculdades Guanambi/BA. Advogado. E-mail: rafael_81oliveira@hotmail.com
} 
Pessoas em todo planeta estão conectadas pela forma digital. A tecnologia vai, cada vez mais, penetrando em todas as áreas de nossas vidas e a fusão do ambiente físico e do virtual trouxe uma gama de novas e complexas transações e relacionamentos.

Não há como impedir, destarte, o surgimento de conflitos. De mais a mais, conflitos são inerentes às relações humanas e têm até mesmo um aspecto positivo, porque quando emergem, buscam-se soluções criativas. Os computadores, por exemplo, surgiram na $2^{\mathrm{a}}$ Grande Guerra, ocasião em que meios de comunicação mais eficientes se faziam necessários, de forma que o desafio está em lidar com os litígios de maneira que não se impeça o progresso e as relações não sejam destruídas. Trata-se, assim, de encarar a resolução de conflitos como aspecto natural das relações humanas.

Nesse contexto e pressupondo-se um modelo pluralista de acesso à justiça, no qual a solução de conflitos pode ocorrer por diversos métodos, auto ou heterocompositivos, desde que adequados às peculiaridades da demanda, importante se faz o estudo dos meios alternativos de solução de conflitos (ADR) bem como dos meios de solução de conflitos online (ODR).

\section{O SURGIMENTO DOS MÉTODOS ODR}

O acrônimo ODR, abreviação de Online Dispute Resolution, é utilizado para o procedimento de resolução de conflitos conduzido com o auxílio da tecnologia da informação, em especial da internet, outros termos usados são online ADR, eADR, IADR e virtual ADR. ${ }^{2}$

Esses métodos surgiram na metade da década de 1990 como resposta às disputas que emer-giram do comércio eletrônico (e-commerce) e no início apenas aplicavam-se os meios de resolução alternativa de conflitos (ADR), ${ }^{3}$ mas em espaço virtual.

Tratava-se, pois de utilizar os meios alternativos de solução de conflitos à distância, usando--se os computadores como meros instrumentos de comunicação.

A doutrina, assim, afirmava que o acrônimo ODR refere-se somente às formas pelas quais certas disputas são introduzidas e gerenciadas e não indica nada diferente da instituição de refe-rência. Os recursos em ODR são devolvidos e decididos pelos mesmos órgãos que ADR. Todos compartilham a natureza extrajudicial e nenhum acesso à justiça é prejudicado. ${ }^{4}$

Conclui-se, portanto, que as ferramentas eram novas, o modelo antigo. Os meios ODR foram inicialmente vistos como pouco relevantes e destinavam-se a serem aplicados em um universo de simples e repetidas demandas virtuais decorrentes do comércio eletrônico.

Essa realidade decorria do fato que, na década de 1990, a internet apenas iniciava sua consolidação como um espaço criativo e lucrativo de comércio e interações humanas. Com o aumento da fusão do mundo físico e do virtual, contudo, estabeleceram-se uma gama de novas e complexas transações e relacionamentos e, um ambiente assim é efetivamente propício para gerar muitas con-tendas. Desta forma, "quando milhões de transações virtuais ocorrem em curto período de tempo, é inevitável que surjam disputas. Com o crescimento do comércio eletrônico, o número de transações vai crescer e também aumentará o número de litígios decorrentes deles". ${ }^{5}$

Percebe-se, então, que os métodos tradicionais de solução de conflitos não seriam mais adequados para as relações virtuais dadas suas peculiaridades. Com pessoas normalmente situadas 
em locais distantes, incapazes de se encontrar face a face, essas disputas haviam de ser resolvidas também em espaço virtual.

Ethan Katsh, professor norte americano e pioneiro no estudo de resolução online de conflito, tão logo participou do primeiro projeto acadêmico sobre o assunto verificou que o espaço cibernético tendia a não ser amistoso.

Isto porque é um ambiente empresarial, competitivo e lucrativo e no qual as transações interpessoais não param de crescer, de forma que as disputas tendem a aumentar. Além disso, com potentes ferramentas de comunicação, processamento e armazenamento de dados, era evidente que se tornaria um ambiente propicio para resolução de disputas. ${ }^{6}$

Ao constatar que uma complexa gama de relações sociais ocorria em espaço virtual, compreendeu que novas ferramentas e recursos de comunicação digital precisariam ser desenvolvidos e aprimorados.

Antonio Carlos Wolkmer (2009, p. 41-42), discorrendo sobre essa virtualização das relações sociais, com o afastamento das barreiras culturais, linguísticas e geográficas, aduz que o processo de mundialização do espaço não nacional é contingência, certamente, dos avanços científicos e das revoluções tecnológicas (informática, telecomunicação, biotecnologia, novas formas de energia, como o laser etc).

Desta forma, a resolução on-line de conflitos é a área que mais cresce no campo de solução de disputas e vem sendo aplicada não apenas para os conflitos que surgem no mundo virtual, mas também para aqueles que provêm no mundo real. ${ }^{7}$

\subsection{O PROJETO PILOTO DE RESOLUÇÃO DE CONFLITOS ONLINE}

O primeiro ensaio significativo de resolução on-line de conflitos foi desenvolvido pelo site E-Bay e utilizou-se de pessoas como mediadores e conciliadores. Elas se comunicavam com as partes envolvidas por e-mail. Verifica-se, assim, que as estratégias utilizadas eram as mesmas do mundo real e isso era de todo razoável porque, quando surge uma nova tecnologia para qualquer área, a tendência é a de que venha espelhar virtualmente o mundo real. O projeto teve início em 1999 e naquela ocasião, Ethan Katsh, Janet Rifkin e Alan Gaintenby, que realizavam pesquisa na Universidade de Massachusetts, atenderam ao pedido do sítio eletrônico E-Bay para criar um sistema de resolução das disputas que surgiam no espaço virtual entre vendedores e compradores. ${ }^{8}$

Disponibilizavam-se, para venda naquela época, no referido site, 1.7 milhões de itens e a cada semana cerca de um milhão de transações ocorriam. Um projeto teste de duas semanas teve, destarte, início, com o nome OOO (Online Ombuds Office) na página do E-Bay.

Em duas semanas, cento e cinquenta reclamações virtuais foram apresentadas. Cerca de cinquenta por cento delas foram resolvidas.

A próxima etapa ocorreu entre os anos 2000 e 2002. As disputas no sítio E-Bay eram direcionadas com um simples click no mouse para a plataforma squaretrend.com que recebeu e lidou com cerca de duzentas mil lides no período. (KATSH, 2002). Os meios ODR, enfim, destinavam-se primordialmente a resolver problemas decorrentes do comércio eletrônico. 
Nesse sentido, dizia a doutrina que o objetivo dos meios ODR era o de favorecer o mercado, principalmente aquele digital, predispondo mecanismos de tutela menos complicados que os judi-ciais e com capacidade para gerir a cota fisiológica dos conflitos. O contencioso que se detecta é o nascente sempre da venda de bens e serviços, porém online. ${ }^{9}$

Vinte anos depois, pode-se dizer que ODR não é mais simples reprodução on-line dos métodos ADR. Uma vez que se comece a fazer algo no espaço virtual, essa prática acaba por desenvol-ver características próprias, afastando-se cada vez mais de seu modelo do mundo real.

\section{OS MEIOS DE SOLUÇÃO DE CONFLITOS EM ESPAÇO VIRTUAL}

As tecnologias digitais estão transformando as relações humanas. Realizamos, atualmente, atividades pela rede mundial de computadores que antes não eram possíveis. Podemos estabelecer relações com pessoas em locais distantes. Ocorre que, ao mesmo tempo em que as transações virtuais são facilitadoras porque nos conectam em um mundo virtual sem fronteiras, essas relações podem gerar conflitos. A criação de um novo espaço inteiramente adequado para a solução dos litígios surgidos das relações virtuais é inevitável.

Os meios ODR consistem em ramo de resolução de disputas que utiliza tecnologia e inteligência artificial. Trata-se da aplicação da tecnologia da informação e comunicação para lidar com conflitos, prevenindo-os e resolvendo-os.

Nesse campo de resolução on-line de conflitos, no início, partiu-se das experiências de solução alternativa de conflitos (ADR), transplantando-as para o mundo virtual. A tendência que se vislumbra, contudo, é a de que no futuro os métodos ODR diversifiquem-se cada vez mais de todos os meios tradicionais de solução de conflitos tornando-se o principal.

Essa nova realidade decorre do uso crescente da inteligência artificial, ${ }^{10}$ da informatização da sociedade e o aumento da capacidade dos computadores.

Não se pode olvidar, ademais, que a maior parte das comunicações on-line deixa rastros digitais. Esses dados gravados oportunizam a sua utilização para que se possa estabelecer os padrões das disputas, permitindo que programas informatizados os analisem e identifiquem aquilo que não seria tão facilmente verificável por seres humanos.

Com isso, é possível estabelecer as principais causas geradoras de conflitos e pensar em meios de evitá-los e solucioná-los, de acordo com suas características, bem como analisar a aptidão de cada método de resolução.

Importante consignar, contudo, que esse crescente arquivo digital tem o inconveniente de acarretar a perda crescente de nossa privacidade. Ocorre que estamos diante de uma nova realidade que não dá mostras de que vá recrudescer. $\mathrm{O}$ mundo se conecta digitalmente de forma crescente e as relações humanas transfronteiriças ocorrem natural e frequentemente. Destarte, a tecnologia vai inexoravelmente penetrando em todas as áreas de nossas vidas. Pensar em solução e prevenção online de conflitos e os métodos ODR como modelo oficial ${ }^{11}$ que se adotará não é mais ficção científica, mas algo inevitável.

\section{O CRESCIMENTO DOS CON LITOS VIRTUAIS}


Em um cenário em que conflitos virtuais aumentam progressivamente, diversas situações podem ser apontadas como causa desse fenômeno. Podemos mencionar alguns exemplos: consumidores ficam insatisfeitos com negociações feitas on-line; as pessoas se preocupam com a preservação de seus dados nessas transações e comunicações; a reputação de empresas é colocada em jogo; as redes sociais são fontes de muitos comportamentos antissociais; governos lutam com problemas de segurança cibernética e todos nós acabamos tendo problemas com o mau funcionamento de websites.

Além disso, há um crescimento contínuo e rápido do comércio no espaço cibernético. Nessa seara, ponderam Ethan Katsh e Janet Rifkin “em que os padrões comerciais ainda não estão solidificados porque há novos comportamentos que muitas vezes diferem das práticas do comércio em espaços não virtuais, a tendência de surgirem conflitos é ainda maior". ${ }^{12}$ Isso nos leva a acreditar que os meios ODR terão maior aplicação do que se imaginava inicialmente.

Além disso, é preciso anotar que a possibilidade de anonimato ou de ausência de encontro real são aptos a dar uma sensação de liberdade. Dessa forma, as pessoas acabam por ser mais agressivas, o que gera mais e mais litígios. Veja-se nessa breve narrativa quantos novos conflitos podem surgir e como podem ser inapropriados os métodos convencionais para resolvê-los satisfatoriamente e em prazo razoável. Essa situação apenas se complica quando pensamos que grande parte dessas relações virtuais se dão além das fronteiras de um país, entre pessoas que não falam a mesma língua e que estão submetidas a governos com suas respectivas soberanias e diplomas legais, de forma que é inviável pensar em soluções tradicionais pelo Poder Judiciário.

Conflitos decorrentes dessas relações irão ocorrer inevitavelmente. Pode-se ponderar se conflitos são bons ou ruins. Ora, o conflito tanto pode ser visto como uma enfermidade social ou como indispensável à evolução humana, já que diante de uma situação conflituosa surgem oportunidades de crescimento pessoal, emerge energia criativa e a possibilidade de se buscar alternativas e mudanças. $^{13}$

Enfim, o aumento das relações sociais e do número de disputas não irá, por si só, transformar uma sociedade em litigiosa. Essa sociedade será reputada litigiosa não em razão do número de controvérsias surgidas, mas por sua tendência de resolvê-los pela forma adversarial.

\section{PLURALISMO E RESOLUÇÃO DE CONFLITOS}

No pluralismo jurídico, parte-se da afirmação que o Estado não é a fonte única e exclusiva de todo direito.

Pluralismo designa, segundo Wolkmer (2001, p. 171-172), a existência de mais de uma realidade, de múltiplas formas de ação prática e da diversidade de campos sociais com particularidade própria, ou seja, envolve o conjunto de fenômenos autônomos e elementos heterogêneos que não se reduzem entre si.

As reformas que visam a criação de alternativas ao sistema oficial d e justiça, segundo Boaventura Souza Santos (1986, p. 27-28), 
estudados pela antropologia e pela sociologia do direito, ou seja, instituições leves, relativa ou totalmente desprofissionalizadas, por vezes impedindo mesmo a presença de advogados, de utilização barata, se não mesmo gratuita, localizados de modo a maximizar o acesso a seus serviços, operando por via expedita e pouca regulada, com vista à obtenção de soluções mediadas entre as partes".

Enfim, conclui o autor lusitano:

o Estado contemporâneo não tem o monopólio da produção e distribuição do direito. Sendo embora o direito estatal o modo de juridicidade dominante, ele coexiste na sociedade com outros modos de juridicidade, outros direitos que com ele se articulam de modos diversos. (WOLKMER, 1986, p. 27).

Em um modelo pluralista, o acesso à justiça, pilar fundamental do Estado de Direito, passa a ser um direito à solução dos conflitos por qualquer meio adequado, deixando-se à função jurisdicional um papel residual.

Afasta-se, assim, o mito da unidade que pressupõe que cada sociedade tem apenas um sistema jurídico e o Estado é o tutor desse. Trata-se de alternativa ao normativismo estatal positivista.

Não se pode olvidar que a sociedade humana é composta por inúmeras personalidades corporativas autênticas, com vontade e consciência própria, podendo cada uma delas formular e criar direitos. O Estado pode até ser a corporação mais importante, mas isso não o legitima a tornar-se a fonte última e exclusiva do direito (WOLKMER, 1986, p. 187).

Trata-se da aceitação pelo Estado de que a função jurisdicional pode ser exercida por terceiro, reconhecendo-se esse exercício como análogo à função judicante, cabendo ao Poder Estatal reservar para si, como exclusiva, apenas a força coativa, ou seja, não reservará de forma absoluta a resolução de controvérsia, somente o fará quanto ao poder de impor o seu cumprimento coativo.

Essa realidade não pode implicar em exclusão ou mitigação da garantia de acesso à justiça, prevista constitucionalmente do art. $5^{\circ}, \mathrm{XXXV}$.

Paula Costa e Silva, a esse respeito, acrescenta que ao Estado, no caso de solução de conflitos fora da esfera jurisdicional, compete "por à disposição da parte que se não conforme com aquele ato, quer porque o entende ilegal, quer porque o entende inválido, meios de controle jurisdicional da decisão proferida por terceiro" (SILVA, 2009, p. 43).

\section{OS MEIOS ADR E ODR COMO PRÁTICAS PLURALISTAS ALTERNATIVAS}

Partiu de Frank Sander ${ }^{14}$, na década de 1970, nos Estados Unidos, o modelo paradigma para a institucionalização dos programas alternativos de resolução de conflitos (ADR). Sua grande intuição foi a de perceber que para cada litígio havia um meio mais adequado de resolvê-lo. Naquela época, o descontentamento dos norte-americanos com os tribunais não se resumia apenas às afirmações de alto custo e duração do processo. $\mathrm{O}$ enfoque ia mais além. Críticos do sistema tradicional de resoluções adjudicadas do Poder Judiciário apontavam outro forte argumento para defender os meios alternativos, qual seja, a inadequação das soluções judiciais que, muitas vezes, apenas traziam alguma compensação econômica, mas não implicavam em futura cooperação das partes. Ponderava-se sobre as dificuldades quanto ao cumprimento das decisões, a qualidade do decidido, 
questionava-se sua aptidão para a pacificação social, manutenção de relacionamentos, bem como o foco na posição das partes, enquanto deveria se dar em seus efetivos interesses e necessidades.

\begin{abstract}
Assim, o surgimento dos meios de resolução alternativa de litígios em todo o mundo, explica Mariana França Gouveia (2014, p.28) está relacionado com a crise do Direito, isto é, com a identificação do Direito com a lei, o que levou à criação de um sistema estatal monopolizador da justiça. Com isso, olvida-se que o Direito surge de diversas fontes e ignora-se o pluralismo jurídico que pressupõe haver instâncias diversificadas de aplicação de soluções jurídicas.
\end{abstract}

No pluralismo jurídico coexistem diversas manifestações normativas não necessariamente estatais (WOLKMER, 2001, p. 288).

Pode-se afirmar, destarte, que a solução de conflitos por métodos alternativos trata-se de "forma de participação popular na administração da justiça” (CAPPELLETTI, 1992, p. 134).

Aponta Cappelletti que, em países com dimensões continentais como o Brasil, com uma população altamente pluralística e estratos sociais profundamente diferenciados, sua utilização tem uma finalidade de legitimação democrática, porque o processo de resolução de litígios perde o caráter incompreensível ao grande público e legitima democraticamente a função. Com a subtração de causas do Poder Judiciário, permite-se, ainda, que haja mais tempo para a solução de demandas complexas que necessitem de efetiva apreciação jurisdicional. Há, nesse campo, outrossim, certo grau de flexibilidade, podendo as decisões serem proferidas não com base em regras rígidas, mas por equidade.

Enfim, em uma sociedade globalizada, é preciso contar com meios diversos de solução de conflitos. Além do modelo oficial Estatal de jurisdição, do qual não se pode prescindir, deve-se introduzir como paradigma um pluralismo do tipo democrático e participativo.

Antonio Carlos Wolkmer (2009, p. 41-42), pontua, ainda, que

\begin{abstract}
diante dos inusitados processos de dominação e exclusão produzidos pela globalização, pelo capital financeiro e pelo neoliberalismo que vêm modificando basicamente relações sociais, formas de representação e de legitimação, ganha relevância reintroduzir politicamente o poder de ação da comunidade, o retorno dos agentes históricos, o aparecimento inédito de direitos humanos relacionados às minorias e a produção alternativa de acesso à justiça, com base no viés interpretativo da pluralidade de fontes.
\end{abstract}

Temos então que num sistema ideal, os meios de solução de litígios são alternativos entre si e sua existência é obrigatória como conjunto efetivamente posto à disposição das partes que devem ser encaminhadas para aquele mais apto à solução (GOUVEIA,

2014, p. 69).

Não se pode olvidar, contudo, que mediação e conciliação devem ser métodos colocados efetivamente à disposição das partes, desde o momento inicial do aparecimento do litígio, como soluções qualitativas e adequadas para cada espécie de conflito e não como propostas quantitativas a serem efetivadas em mutirões ou semanas de conciliação, normalmente quando o processo já tramita há anos, consumiu recursos de toda ordem do Judiciário, bem como minou a resistência da parte mais fraca (ZANFERDINI, 2012, p. 258).

A ideia não se reduz, portanto, ao escopo de proporcionar apenas métodos mais rápidos e menos custosos de soluções de litígios. Trata-se de tornar disponível uma diversidade de meios 
efetivamente postos à escolha das partes envolvidas no conflito, adequados às peculiaridades deles, permitindo-lhes participação ativa em todo o procedimento.

Ora, não se pode deixar de anotar que "el poder de las partes para solucionar ellas mismas sus próprios conflitos es lá expresión de una sociedade democrática" (ROSA VIGA, 2010, p. 105).

Conclui-se, assim, que meios alternativos de solucionar conflitos contribuem para a democratização da justiça porque permitem maior participação dos envolvidos.

\section{LIMITAÇÕES DOS MÉTODOS ADR E CRESCIMENTO DOS MEIOS ODR}

Os métodos ADR funcionam bem quando as partes estão em um mesmo país, podem se locomover até uma reunião face a face, em tempo real e simultâneo, dentro de uma jurisdição específica, submetidos a um mesmo ordenamento jurídico, que tenha poder de coerção em caso de inadimplemento daquilo que for resolvido por esses métodos.

Ainda nessas situações, muitas vezes em países como o Brasil, de proporções continentais, trazer as partes para um mesmo ambiente tem alto custo e, dependendo do valor envolvido na disputa, esse deslocamento nem sequer compensa. Essas barreiras físicas não existem no mundo virtual.

Não se pode olvidar, outrossim, que o Poder Judiciário vem perdendo sua efetividade para lidar com as necessidades das partes porque os custos são desproporcionais e os procedimentos morosos e complexos. Os meios ODR emergiram como a resposta natural para essas situações e com o objetivo de proporcionar um efetivo meio de superar essa lacuna.

\section{TECNOLOGIA E A RESOLUÇÃO DE CONFLITOS}

A tecnologia nos trouxe a possibilidade de estabelecermos relações pessoais virtuais de toda ordem. Criou-se o espaço cibernético. ${ }^{15}$ Trata-se de invenção humana em que uma combinação de lugares estão disponíveis em uma tela. É possível ter acesso a livrarias, lojas, cassinos, leilões, serviços de entrega e mais uma série de opções na forma eletrônica. Pela internet podemos fazer cada vez mais coisas sem necessidade de deslocamento físico.

Estabelecidos esses espaços virtuais, foi preciso repensar o modelo tradicional de resolução de disputas. A tecnologia pode auxiliar com esforços diversos: debate, avaliação, explicação, discussão, identificação, definição, organização, esclarecimentos, coleta de dados, propostas, publicação, elaboração de esquemas etc.

Afirma Colin Rule $(2002$, p. 7) que não há dúvidas de que o melhor meio para solucionar a solução de conflitos advindos das relações virtuais, consiste na utilização dos meios ODR. ${ }^{16}$ Podem ser apontados os seguintes benefícios de seu uso: as demandas são processadas de forma mais rápida e resolvidas em prazo menor, com custos mais baixos. Futuros litígios são evitados quando as partes aprendem a se comunicar melhor umas com as outras. Os envolvidos ficam mais satisfeitos com o processo de resolução e seus resultados, as relações tendem a ser preservadas, em razão da confiança de que é possível resolver eventuais problemas, soluções criativas costumam ser encontradas e as partes com maior frequência cumprem o que estabeleceram. 
A resolução on-line de conflitos tem, destarte, baixo custo porque não há deslocamento de pessoas. Partes e mediador/conciliador/árbitro ou juiz podem estar distantes e se aproximarem pelo mundo virtual e isso pode se dar até mesmo, em alguns casos, sem sincronismo (ZANFERDINI; NASCIMENTO JUNIOR, 2018, p. 183).

Nessa seara, "ODR platforms may improve access to justice for those litigants who would otherwise be unable to settle small causes" (ZANFERDINI, OLIVEIRA, 2015, p. 73).

\section{NOTAS}

1 All societies and human social groups (including both families and nations) need to have effective ways to resolve disputes that arise. Online communities were and are no different. (RULE: 2002; p. 7)

2 ODR-term used for ADR process conducted with the assistance of information technology, particularly the net. Other terms used are OnlineADR, eADR, IADR, virtual ADR (E-justice: information and communication technologies in the court system. (MARTINEZ; FRABRA: 2009; p. 95). (Tradução nossa)

3 O acrônimo ADR designa "alternative dispute resolution", que podemos traduzir como métodos alternativos de resolução de conflito. Nada obstante o uso internacional e majoritário do acrônimo "ADR", outros termos são utilizados "MASC" («mecanismos alternativos de solução de conflitos» ou «modalidades alternativas de solução de conflitos»), "MARC" (mecanismos alternativos de resolução de conflitos).

4 "In effetti i'acronimo ODR (online dispute resolution) indica solo le modalità con cui si introducono e vengono gestite certe controversie, e non indica qualcosa di diverso dall'istituto di referimento. I ricorsi in ODR vengono devoluti e sono decisi dagli stessi organismi di ADR; condividono la natura extragiudiziale dell'eventuale sistemazione; in difetto della quale, no è pregiudicato l'acesso alla giustizia". (CAPPELLETTI:2012; p. 278).

5 "When millions of transactions are taking place in short periods of time, it is inevitable that disputes will occur. As e-commerce grows, the level of transactions will grow, and the number of disputes occurring also will increase". (KATSH et. al.: 2018. p. 725).

6 "Cyberspace seemed to us to be too active, too entrepreneurial, too competitive, and too lucrative a place for it not to have many conflicts". (KATSH: 2002, ONLINE).

7 Now, some twenty years later, ODR is the fatest growing area of dispute resolution, and it is increasingly being applied to other areas, including off-line and higher value disputes" (What we know and need to know about online dispute resolution. Disponível em: <www.americanbar.org>. Acesso em: 21 fev. 2018. p. 329). (Tradução nossa).

8 "This Article arose out of a project conducted during the spring of 1999 in which we attempted to bring the skills of a trained mediator to disputes arising in the setting of eBay, the largest online auction site on the web. Our main goal was to ascertain how effective an online mediator could be when interaction occurred without face-to-face meetings. Yet we also recognized that however successful or unsuccessful we were in this process, this would be only the first in many efforts to find appropriate tools and resources for confronting large-scale online conflict.”(KATSH et. al.: 2018, ONLINE)

9 Lo scopo dell'ODR è ancora quello di favorire il mercato. Specie quello digitale, predisponendo meccanismi di tutela meno complicati dell'azione in giudizio e capaci di gestire la quota fisiológica di conflitti (considerando n.2 e 5). Il contenzioso che releva è quello nascente sempre dalla vendita di beni o di servizi, di matrice però online. Offerta del professionista e ordine del consumatore devono essere insomma rigorosamente elettronici (art. 4, lett. c). (CAPPELLETTI: 2012; p. 278). 
10 Inteligência artificial é um ramo da ciência da computação que se propõe a elaborar dispositivos que simulem a capacidade humana de raciocinar, perceber, tomar decisões e resolver problemas, enfim, a capacidade de ser inteligente. (CIRIACO, 2018, ONLINE)

11 Estudo levado a efeito no Reino Unido afirma que a projeção é a de que no ano 2022 a maior parte das disputas cíveis na Inglaterra e Gales será resolvida através de procedimentos online. Com isso, acredita-se que haverá maior acesso à justiça e se permitirá a resolução efetiva, rápida e justa dos conflitos. (THOMAS; TOMLINSON, 2018, ONLINE).

12 "Disputes are more likely to occur in new enviroments where established processes understandings have not solidified". (KATSH, RIFKIN, 2001; p. 4).

13 Elena I. Highton afirma que dentre os benefícios do conflito como fator de mudança pode-se incluir:1- O conflito se opõe ao engessamento do sistema social ao exercer uma pressão a favor da inovação e criatividade; 2- Quando se impede o curso natural do conflito podem ser tomadas decisões prematuras e, por consequência, pobres; 3- O desestímulo às diferenças não ajuda e isso é o que acontece quando cada parte tem tanto medo de contrariar o outro que não expõe o seu ponto de vista, nem sequer para tentar fazer com que o outro entenda; 4 - $O$ conflito às vezes é necessário para se alcançar a justiça; 5 - Os conflitos são essenciais para a evolução da sociedade. Como aspectos negativos dos conflitos aduz que ocupam tempo e energia que poderiam ser utilizados para outras finalidades. Os conflitos podem ocasionar prejuízos diretor e indiretos. São custos diretos, porque exemplo, aqueles decorrentes de processo judicial e todo seu aparato e indiretos podem ser apontados o tempo para preparar suas posições e para obter provas. A quebra de relações sociais também pode ser apontada como prejuízo decorrente dos litígios. (HAMMURABI: 2010; p. 476).

14 "Frank Sander's 1976 speech at the Pound Conference on "The Causes of Popular Dissatisfaction with the Administration of Justice" (Sander 1976) is widely seen, particularly within the legal academy, as the"big bang" moment in the history of alternative dispute resolution (ADR). At the Pound Conference, Frank articulated his observation that traditional litigation systems process only certain kinds of disputes effectively. He suggested that the remaining types of disputes might better be addressed through other mechanisms." (MOFFITT: 2006, ONLINE)

15 Termo criado pelo escritor Willian Gibson em seu romance Neurocenter e hoje utilizado para referir-se ao espaço abstrato construído pela rede de computadores. Disponível em: $<$ www.dicio.com.br $>$. Acesso em: 23 jun. 2018.

16 There is no debate over whether or not online dispute resolution is the best option for providing redress on the Internet.

\section{CONCLUSÃO}

O comércio e as demais relações interpessoais em espaço cibernético tendem a crescer em grandes proporções e os meios ODR vêm se revelando os mais adequados para lidar e resolver as disputas que surgem nesse contexto.

No universo cibernético, a experiência mostra que gradualmente as comunicações e relações virtuais vêm aumentando e se aperfeiçoando e naturalmente as ferramentas virtuais passarão a ser vistas também como adequadas para a solução dos conflitos. Em um mundo sem barreiras físicas, há uma forte tendência de que tribunais e centros de solução alternativa de conflitos virtuais serão a realidade e o meio mais usual para resolução de disputas.

Não é possível antever quando isso se dará, mas pode-se afirmar que é uma realidade para a qual caminhamos inevitavelmente. 
O uso desses meios alternativos, quer sejam virtuais (ODR) ou presenciais (ADR) não implica na redução ou exclusão da proteção legal ou em limitação do acesso à justiça.

Diante da crise do Poder Judiciário, a sociedade cria novas formas de resolver conflitos, mais adequadas às peculiaridades desses e, numa sociedade pluralista é preciso fomentar a existência de diversos métodos de resolver litígios. Os meios ODR são eficientes como instrumentos de pacificação social. O papel dos litigantes na busca de soluções implica em atuação co-participativa e conduz a uma maior possibilidade de cumprimento espontâneo do decidido.

A tendência, destarte, é de que os métodos ODR serão o modelo oficial de resolução de disputas e contribuirão para expandir o acesso à justiça.

\section{REFERÊNCIAS}

CAPPELLETTI, Mauro. Problemas de reforma do processo civil nas sociedades contemporâneas. Revista de Processo. n. 65, São Paulo, RT, 1992.

CAPPELLETTI, Mauro. Superabili ambiguità. Le proposte europee in tema di ADR e di ODR, REPRO 206, ano 2012.

CIRIACO, Douglas. O que é inteligência

. Disponível em: $<$ https://www.tecmundo.com.br/intel/ 1039-o-que-e-inteligencia-artificial-.htm>. Acesso em: 09 jul. 2018.

GOUVEIA, Mariana França. Curso de resolução alternativa de litígios. 3. ed. Coimbra: Almedina, 2014.

HIGHTON, Elena I.Gerenciamento del conflitcto y diseno de sistemas de resolucion de disputas em el âmbito de las organizaciones empresaliales, 1. ed. Buenos Aires: Hammurabi, 2010.

KATSH, Ethan. Online dispute resolution: the next phase. p. 2. Lex electronic. v. 7, n. 2, 2002. Disponível em: < www.lex-electronic.org/articles/v7-2/>. Acesso em: 22 fev. 2018

KATSH, Ethan; RIFKIN, Janet; GAITENBY, Alan. E-Commerce, E-Disputes and E-Dispute Resolution: In the shadow of 'eBay Law'. Disponível em: $<$ http://www.umass.edu/cyber/katsh.pdf $>$. Acesso em: 22 jun. 2018.

KATSH, Ethan; RIFKIN, Janet. Online dispute resolution: resolving conflicts in cyberspace. San Francisco, Jossey-Bass, 2001.

MARTINEZ, Agustí Cerrilo; FRABRA, Pere. Information Science Reference. New York, 2009

MOFFITT, Michael L. Special Section: Frank Sander and His Legacy as an ADR Pioneer Before the Big Bang: The Making of an ADR Pioneer. Negotion Journal. outubro de 2006. Disponível em: $<$ https://law. uoregon.edu/images/uploads/entries/Michael Moffitt-Before the Big Bang-The Making of an ADR Pioneer.pdf $>$. Acesso em: 22 jun. 2018.

ROSA VIGA, Los jueces y las nuevas formas de hacer justicia. In Resolución alternativa de Hamurabi: Buenos Aires, 2010.

RULE. Colin. Online Dispute Resolution for Business, San Francisco: Jossey-Bass, 2002.

SANTOS, Boaventura de Sousa. Introdução à sociologia da administração da justiça. Revista Crítica de Ciências Sociais, n. 21, nov. 1986.

THOMAS, Robert; TOMLINSON, Joe. The digitalisation of Tribunals: What we Know and we need to Know. Disponível em: <www.puliclawproject.org.uk> . Acesso em: 21 jun. 2018.

VILALTA, Aura Ester. ODR and E-Commerce. Disponível em: <https://www.mediate.com/articles/ ODRTheoryandPractice7.cfm>. Acesso em: 21 jun. 2018.

ZANFERDINI, Flávia de Almeida Montingelli. Desjudicializar conflitos: uma necessária releitura do aces- 
so à justiça. Novos Estudos Jurídicos, [S.1.], v. 17, n. 2, p. 237-253, ago. 2012. ISSN 2175-0491. Disponível em: <https://siaiap32.univali.br/seer/index.php/nej/article/view/3970/2313>. Acesso em: 30 jun. 2018. doi:http://dx.doi.org/10.14210/nej.v17n2.p. 237-253. p. 258.

ZANFERDINI, Flávia de Almeida Montingelli; NASCIMENTO JUNIOR, Vanderlei de Freitas. Novas tecnologias e a solução online de conflitos em uma sociedade de massa. São Carlos: CPOI/UFSCar, 2018. In ZANQUIM JUNIOR, José Wamberto; CHACUR, Rachel Lopes Queiroz (organizadores). Novos direitos: direito e justiça. São Carlos: CPOI/UFSCar, 2018. p. 174-190.

ZANFERDINI, Flávia de Almeida Montingelli; OLIVEIRA, Rafael Tomas de. Online dispute resolution in Brazil: are we ready for this cultural turn? Revista Paradigma, a. XX, v. 24, n. 1, p. 66-80. jan./jun. 2015. ISSN 2318-8650. Disponível em: <http://www9.unaerp.br/revistas/index.php/paradigma/article/ view/589/548>. Acesso em: 11 jul. 2018.

WOLKMER, Antonio Carlos. Pluralismo Jurídico e Novas Perspectivas dos Direitos humanos. Jurisprudência Catarinense, Florianópolis, v. 35, n. 118, jan./mar. 2009. Disponível em: $<$ http://bdjur.stj. jus.br/dspace/handle/2011/92207>. Acesso em: 3 set. 2018.

WOLKMER, _. Pluralismo jurídico: fundamentos de uma nova cultura no direito. 3. ed. São Paulo: Editora Alfa Omega Ltda, 2001.

Data de submissão do artigo: Junho de 2019

Data de aceite do artigo: Dezembro de 2019 